\title{
Um filme com muitas portas
}

Carlos Império Hamburger, o Cao, nasceu em São Paulo em 1962. Seu segundo longa-metragem, o aclamado $\mathrm{O}$ ano em que meus pais saíram de férias, raro sucesso simultâneo de público e crítica, emocionou com riso e lágrimas a platéia que foi conhecer a história de Mauro, um garoto de 12 anos que é deixado pelos pais no apartamento do avô em São Paulo, no bairro do Bom Retiro - reduto de imigrantes judeus -, às vésperas da Copa do Mundo de 1970 e em plena repressão do governo ditatorial militar do Brasil. Seu primeiro filme foi Castelo Rá-tim-bum, O Filme (1999), que ganhou críticas calorosas e grande aprovação do público, tanto infantil quanto adulto. $\mathrm{Na} T \mathrm{TV}$, o diretor foi responsável por sucessos como a premiadíssima série infantil Castelo Rá-tim-bum (1995), da TV Cultura, que recebeu prêmios em todo o mundo, e pela direção de um episódio na elogiada série Cidade dos Homens (2004), da TV Globo. Mais recentemente, foi o responsável pela criação e direção-geral da série Filhos do Carnaval (2006), com produção da O2 Filmes e da HBO. Antes dos longas, Hamburger dirigiu o curta $\mathrm{O}$ Menino, a favela e as tampas de panela (1995), o documentário Tietê (1993), as animações Caçada no Pantanal (1990), A garota das telas (1989) e Frankenstein Punk (co-direção de Eliana Fonseca, de 1989), com os quais ganhou prêmios no Brasil e no exterior. Nesta entrevista ele fala da sua relação com o cinema e a televisão, e das possíveis saídas para uma audiência mais crítica nas salas de aula.

C \& E: Cao Hamburger, no seu último filme, O ano em que meus pais saíram de férias, qual era o seu principal objetivo?

Cao Hamburger: Acho que era contar uma história bem contada - não tinha muitas expectativas. Esta é a qualidade do filme, não ser muito pretensioso. Queria contar bem a história e preservá-la. Uma história que tem diferentes pontos de vista: multifacetado, com diversas maneiras de se ver o filme, de entender. Pode-se entrar nele por diferentes portas. Outro objetivo era fazer um filme que desse tempo ao espectador, que cada um sentisse a história a sua maneira; queria um filme com um tempo, um exercício quase de cinema, arejado, com espaço entre as cenas, entre as emoções, e tal. Queria um filme com personagens e história fortes. Acho que era isso.

C \& E: Qual era o público que você pretendia atingir?

Cao Hamburger: O público-alvo sempre foi o adulto. Depois nós focamos também, já na campanha de lançamento, os jovens. Queria fazer um filme sobre a infância, mas para os adultos. Entretanto as crianças têm adorado... as de 10, 12 anos têm gostado muito. 
comunicação \& educação • Ano XII • Número 2 • maio/ago 2007

C. \& E: Uma pergunta do Conselho de Publicação da revista: por que você optou por tratar da década de 1970 pelo olhar de uma criança?

Cao Hamburger: Porque foi assim que eu a vivi. Tem muito do meu olhar e das pessoas que fizeram o filme comigo. Tem muito do meu olhar, sim.

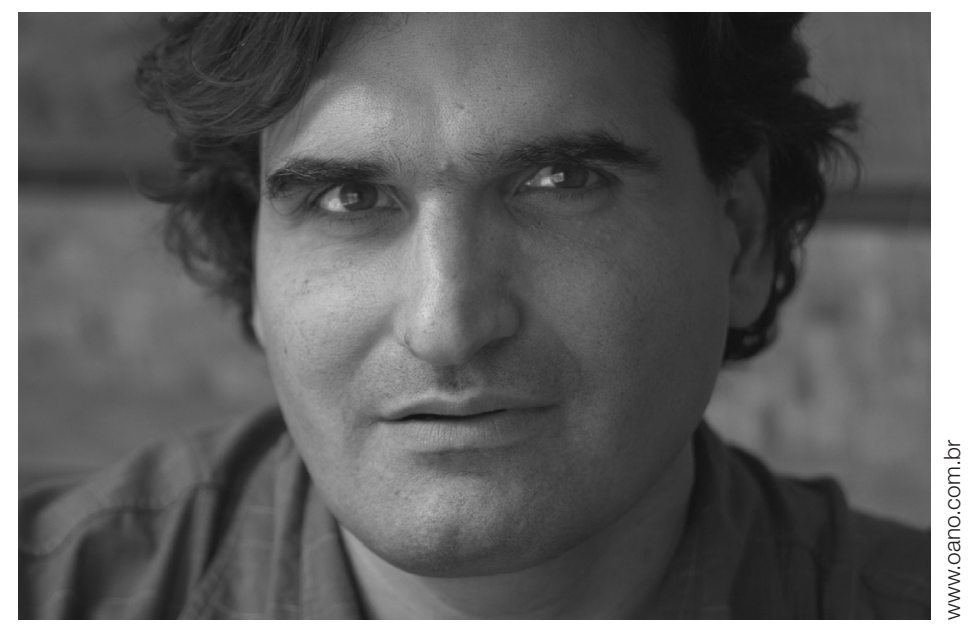

C \& E: O fato de você fazer essa revisão histórica, a partir do olhar de uma criança, não dá ao filme certa ingenuidade diante dos problemas da época?

Cao Hamburger: Não sei dizer, pode ser que dê. Porém, eu não estava fazendo um filme sobre os problemas políticos da época, mas sobre a história de um garoto. Então, acho que quem for ver o filme esperando um estudo sobre a situação política da época vai se frustrar muito; não é sobre isso, este nunca foi meu objetivo. Para mim, o objetivo sempre foi contar uma história muito bem contada de um garoto passando da infância para a adolescência numa situação pessoal crítica para ele, no meio desse momento conturbado da vida brasileira e mundial também, no auge da Guerra Fria, e tal. Não acho que a visão seja ingênua... é coerente com o ponto de vista do garoto. Dessa época só me interessava o que estava influenciando, ou atuando, ou reverberando na vida do garoto, porque o garoto é que era o meu foco.

C \& E: O que há da sua experiência na televisão nesse filme?

Cao Hamburger: Muito pouco. Enfim, a gente nunca sabe de onde vem nossa bagagem, mas da linguagem de televisão, há muito pouca. Tive na televisão

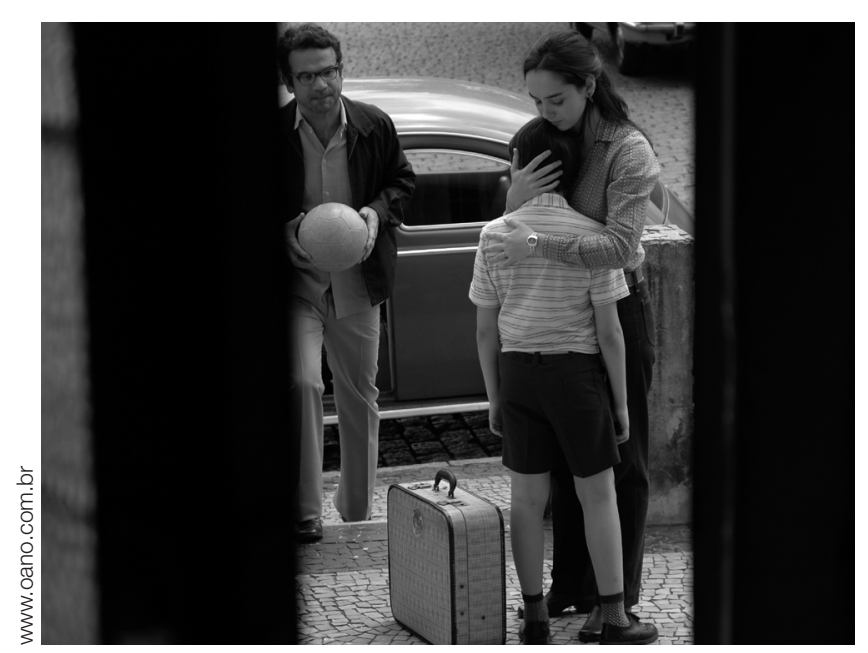
a experiência de trabalhar com criança, mas os registros, as freqüências de trabalho são muito diferentes.

C \& E: No filme, quando você mostra o papel da televisão na sociabilidade das pessoas no bairro, na pontuação da própria história brasileira, isso foi intencional ou não?

Cao Hamburger: De certa forma foi intencional colocar 
a televisão no filme, porque é sobre a infância da televisão brasileira também; é sobre a época em que ela estava presente. Considero-me parte da geração da televisão, do personagem também... Cresci assistindo à televisão. Era a grande novidade da época, assim como para meus filhos são o computador, o videogame, e para os meus pais talvez tenha sido o rádio. A televisão era o grande veículo ali, não podia faltar; acho que faz parte da caracterização da época. A Copa do Mundo de 1970 foi a primeira a ser transmitida ao vivo, por isso a TV fez parte da história, sempre fez.

C \& E: Você acha que a televisão está perdendo esse espaço?

Cao Hamburger: Está, sinto aqui em casa pelos meus filhos... está perdendo para o computador. Mas vai demorar a perder sua importância. Não sabemos direito o que vai acontecer, mas penso que a televisão e o computador vão, de alguma maneira, se juntar, virar uma coisa só... isso é só expectativa.

C \& E: Como foi trabathar com crianças?

Cao Hamburger: Gosto muito! Já faço esse trabalho há algum tempo e acho muito legal. Talvez tenha sido o ápice de um processo que venho desenvolvendo há dez anos. Esse trabalho foi o mais bem realizado, no sentido de trabalhar com

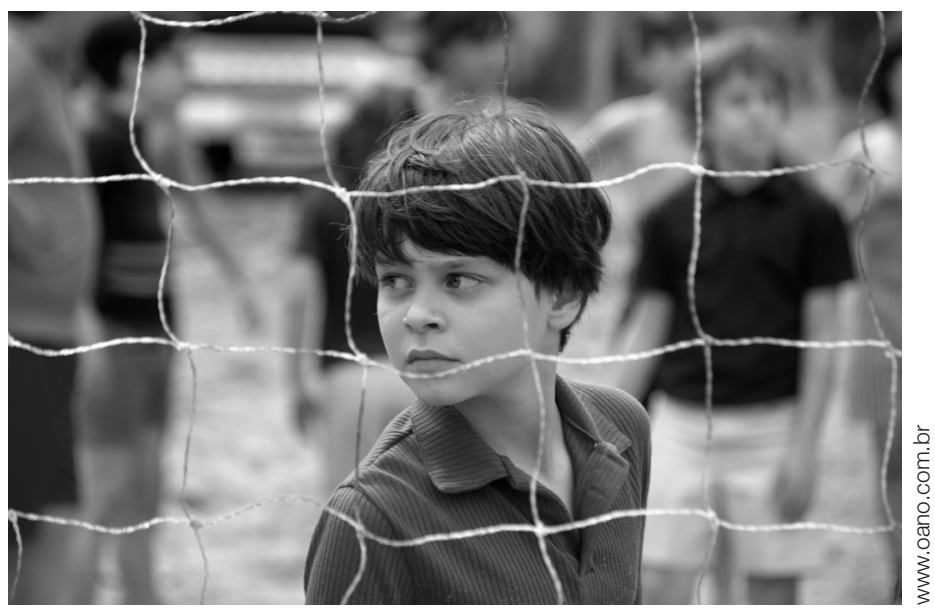
crianças.

C \& E: Peter Burke diz que parte dos preconceitos que existem hoje em relação ao Brasil é fruto do cinema brasileiro, que tem procurado exportar violência e o que ele chama do lado infernal do Brasil. Você concorda, como cineasta? O cinema brasileiro oferece um retrato preconceituoso do Brasil ou ajuda a transmitir esse preconceito?

Cao Hamburger: Se o cinema está contribuindo para isso, não é culpa do cinema; é culpa do Brasil, porque o cinema tem um pouco essa função de pesquisar e mostrar a realidade. Enfim, o Brasil é muito violento e muito pobre, muito desigual; seria estranho se o cinema brasileiro não estivesse falando disso ou não estivesse usando isso como assunto. Acho que, nesse caso, as críticas deveriam ser contrárias. Agora, o cinema não deve apoiar-se só nisso, e esse filme vai um pouco nesse sentido: apesar de falar de Ditadura e de outras coisas ruins que acontecem no País, não procuramos ressaltar isso. Não acho que seja uma boa política incentivar o cinema brasileiro a mostrar só o lado bom do País... isso é uma coisa meio estranha. Se vier, se for natural os artistas fazerem, é 
bem-vindo. E há comédias, está cheio de comédias e de filmes como O Auto da Compadecida, que mostram um Brasil mais brejeiro, mais leve. Pode ser uma tendência fazer cinema com histórias da classe média, porque, afinal, cansa um pouco tratar do mesmo viés. O que aconteceu, de fato, é que o sucesso do filme Cidade de Deus - que é um filme excepcional, de uma qualidade incrível, considerado um dos 10 melhores já realizados no mundo - ocorre por abordar uma realidade brasileira, baseada no livro de um autor que viveu aquilo. Não é nenhuma mentira, só que fez um sucesso tão grande que essa situação das favelas no Rio de Janeiro passou a ser conhecida no mundo. Não acho isso ruim, é muito bom que as pessoas saibam, especialmente através de um filme tão bem-feito. Mas há espaço para outro tipo de cinema também. O ano em que meus pais saíram de férias vai um pouco nesse sentido. Os poucos estrangeiros que assistiram ao filme comentaram que a história - um país de classe média com imigrantes - não parece brasileira, porque não corresponde à visão que eles têm do País, e tal...

C \& E: Maria Lourdes Motter, que é especialista em telenovela e faz parte do Conselho da revista, ficou muito impressionada com a narrativa sonora do seu filme - lembrou-se de um momento em que o tropel dos cavalos e o gol da vitória se mesclam. Ela pergunta: como foi construir a narrativa sonora do filme?

Cao Hamburger: É uma parte do filme que gosto muito de trabalhar - chamamos esse trabalho de desenho de som e trilha sonora. Como esse é um filme que tem

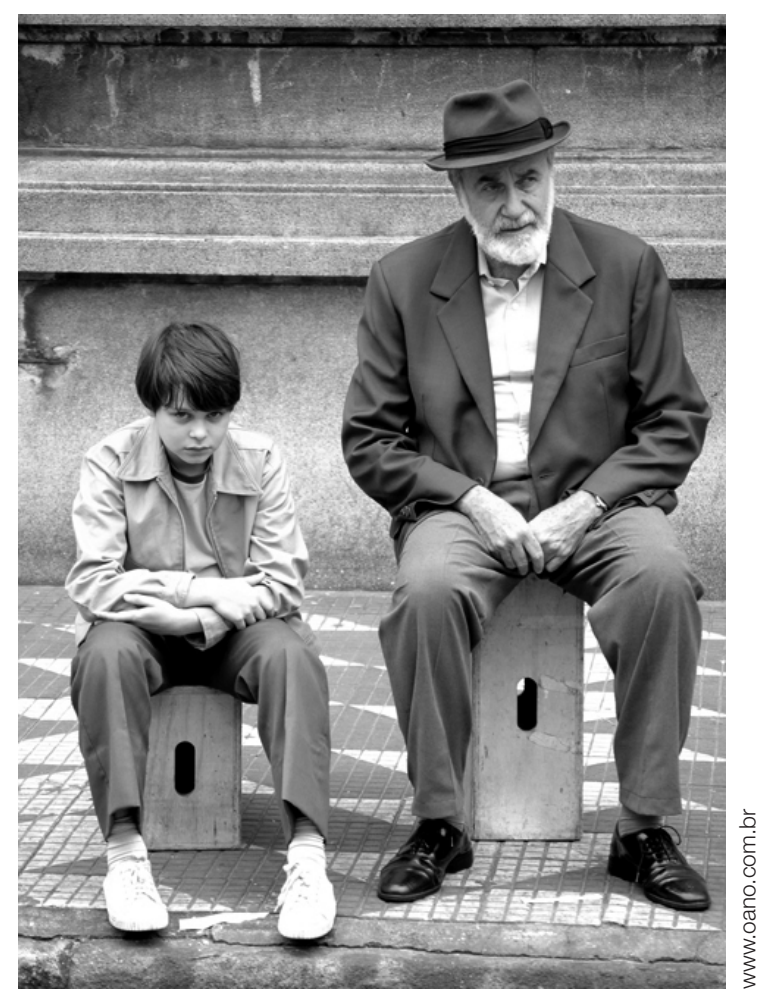
muito pouco diálogo, ele dá espaço para que o som faça parte da narrativa do filme. Deve ser por isso que ela notou, porque o filme foi concebido para que isso fizesse parte dele ou da narrativa. A pouca quantidade de diálogos permitiu e deu espaço para essa outra narrativa mais subjetiva.

C \& E: Outra pergunta da Maria Lourdes Motter é a seguinte: no seu filme, a convivência racial e religiosa entre segmentos diferentes é positiva. Você acredita que seja assim no Brasil? 
Um filme com muitas portas - Cristina Costa e Consuelo Ivo

Cao Hamburger: Acredito, sou filho dessa convivência e acho que ela existe de fato, como uma base da cultura brasileira, formada fundamentalmente pela mistura cultural, pela miscigenação. Acredito que não necessariamente de uma miscigenação prática ou física das raças, mas de culturas. Não acho que seja um paraíso das raças aqui, não, mas sinto que a cultura brasileira é formada por essas questões.

\section{C \& E: Há tolerância?}

Cao Hamburger: Pode até ter uma intolerância, mas que há uma mistura, um caldeirão cultural, há. A intolerância pode até fazer parte desse caldeirão, mas vivemos num país, numa cultura muito cheia de influências de todas as pessoas que moram aqui. Vejo a cultura brasileira como um caldeirão de todas essas raças. Mas não quer dizer que não haja nem racismo nem intolerância. Creio que há, mas mesmo assim o País é formado por todas as culturas juntas.

C \& E: Como foi a relação com as escolas para selecionar atores entre os alunos? Como a escola se relacionou com isso?

Cao Hamburger: Fomos com muito cuidado. Apresentamos o projeto muito detalhadamente, o que facilitou o processo. A produtora de elenco, que é a Patrícia Faria, achou que o melhor lugar para encontrar os atores mirins seria na comunidade judaica. Focamos a procura nas escolas judaicas e nos clubes também. Lá fizemos uns $70 \%$ dos mil testes com crianças. Creio que foram três escolas judaicas em São Paulo... mas foi fácil, eles colaboraram, nos ajudaram, até. Tivemos tempo, não chegamos em cima da hora, e isso é muito importante quando se trabalha com as escolas, porque é tudo muito diferente, o tempo da escola e o tempo do cinema. Sabendo disso, começamos bem cedo, com bastante tranqüilidade, e todos nos ajudaram bastante.

C \& E: Como tem sido a sua relação com a educação de uma maneira geral? Tem havido aceitação, aprovação por parte da escola, ou resistência?

Cao Hamburger: Só ouço aprovação. Fiz alguns trabalhos em que uni a qualidade do entretenimento com o educativo; então, creio que sempre recebi aprovação, nunca tive problemas com as escolas.

C \& E: Muitos autores vêem a televisão dos anos 1970 de uma maneira bastante nostálgica, achando que o grande momento da televisão brasileira foi naquela década, e que depois disso ela teria se degradado ou perdido o caráter experimental de ousadia, inclusive de receber autores de teatro, diretores de cinema, que não podiam atuar por causa da censura, da ditadura etc. Você concorda com essa visão?

Cao Hamburger: Quando falamos do passado, existe essa coisa nostálgica que nos pega sem percebermos, e aí valorizamos coisas que, às vezes, é por saudade da época toda. Posso até concordar em certo sentido, porque atualmente a televisão está passando por uma crise muito forte, está-se mudando o veículo; há uma alteração técnica e política muito importante, e ninguém sabe muito 
comunicação \& educação • Ano XII • Número 2 • maio/ago 2007

bem o que vai acontecer. São questões sobre a televisão digital, a cabo e a aberta... É um momento de crise, mas ainda imagino que a televisão faça coisas muito boas no Brasil; é uma televisão de boa qualidade, principalmente a Rede Globo. Acredito que é uma situação momentânea, e o que vai sobrar disso tudo não se sabe. Lembro-me de que na década de 1970, 1980, a televisão era muito malvista pelos educadores, pelos intelectuais, e tudo. Meu pai chamava a televisão de caixa maldita, "Desliga essa caixa maldita!"...

C \& E: E os filhos dele foram trabalhar com televisão, diretamente ou indiretamente...

Cao Hamburger: A televisão é um veículo muito invasivo, está dentro da sua casa e é passível de muita crítica. Há de se criticar mesmo a televisão, sempre. É uma das maneiras de defender ou de criar defesas para os espectadores. A crítica à televisão deve estar sempre em dia, criar espectadores críticos; isso é muito importante, não só para a televisão, mas, atualmente, até para a internet.

Não tenho uma nostalgia

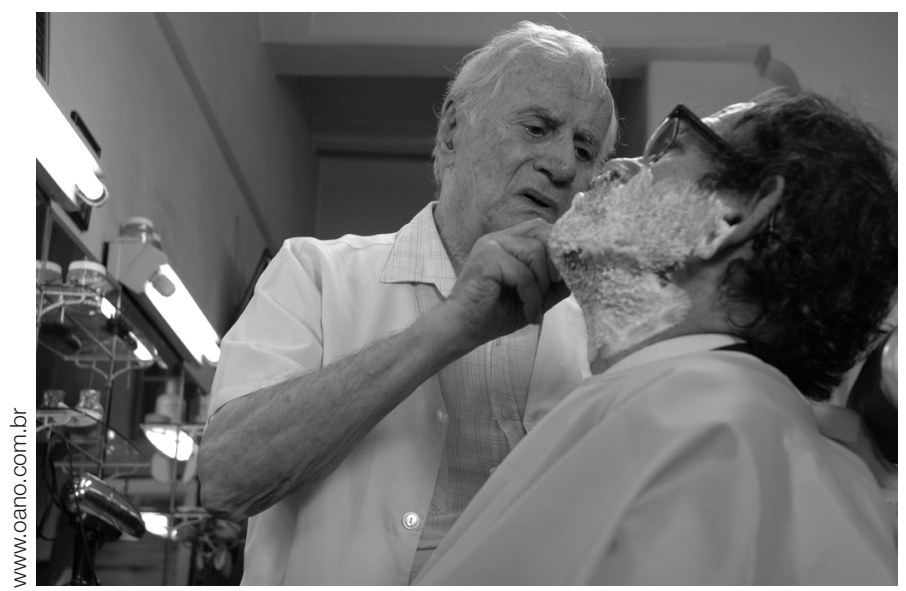
da televisão antiga, apesar de me lembrar de muitos programas da televisão dos anos 1970, 1980, de que gosto muito...

C \& E: Por exemplo?

Cao Hamburger: Ontem saiu a foto de Dancing Days, que é uma novela com a Sônia Braga. Havia novelas do Dias Gomes... coisas um pouco mais ousadas. Atualmente temos séries como Antônia, Cidade dos Homens, que não existiam na época, ou a Regina Casé fazendo esse trabalho com a periferia. Programas infantis como o Castelo Rá-tim-bum, na época havia o Vila Sésamo, que era originalmente uma criação americana. Tenho medo da nostalgia. Creio, na verdade, que estamos passando por um momento em que as artes e as comunicações de massa estão em certa crise... não é só a televisão, mas o cinema também. Não se fazem filmes tão marcantes há muito tempo. A música também... é um momento, e no mundo inteiro. Alguma coisa vai acontecer daqui para a frente, imagino... na literatura também. São ciclos, na verdade. Isso é mais do que comparar uma época com a outra. Não houve o Iluminismo, que foi uma grande época? Depois veio a Idade Média, considerada a idade das trevas... Acho que a humanidade vai produzindo cultura e comunicação meio em ciclos. 
Um filme com muitas portas - Cristina Costa e Consuelo Ivo

C \& E: Hoje em dia as câmeras digitais e os celulares estão colocando em crise o conceito de imagem. No que a imagem está se transformando na atualidade?

Cao Hamburger: Nunca, em nenhum outro momento, a imagem gravada, o audiovisual, foi tão presente na vida das pessoas. Um telefone faz filmes, câmeras de segurança, câmeras da internet captam imagens... Nunca foi tão fácil fazer imagens e nunca vimos tantas. Enfim, uma característica da época, do mundo digital. Sinto que estamos na fase que a televisão esteve na década de 1970, com o aparelho à válvula, com aqueles problemas todos de transmissão e qualidade das imagens. A tecnologia digital está nessa fase de válvula ainda e, rapidamente, daqui a alguns anos, o digital vai ser muito mais poderoso; é uma tendência e não tem volta. Isso está mudando muito todos os veículos de comunicação audiovisual. Não só a televisão, como o cinema, e para um lugar que não sabemos direito qual seja. Então, estão todos meio perdidos.

C \& E: Você diz que seu filme foi pensado para o adulto. Você falou com o adulto ou para a criança do adulto?

Cao Hamburger: Somos

uma coisa só, mas acho que falar de infância é forte para qualquer idade. Por isso, imagino que ela tenha esse público tão abrangente. A criança falar sobre criança é meio fácil de entender; agora, você falar sobre criança para jovens e adultos, sempre vai ser forte, porque é uma fase da vida que é muito determi-

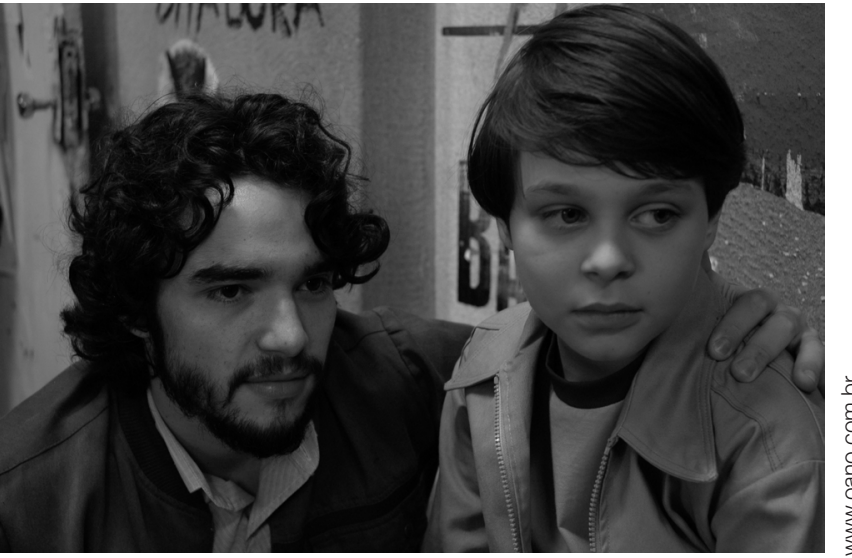
nante, pelo menos vejo isso nas pessoas. São emoções muito básicas, muito fortes que vêm à tona, quando você fala de infância. E creio - vocês são educadoras, devem saber melhor -, como leigo, que a infância é uma fase da vida muito determinante para nossa formação emocional, psicológica e até ética. Creio que é por esse motivo que o filme agrada tanto.

C \& E: Adilson Citelli, outro membro do nosso Conselho de editores e que escreve para educadores, costuma dizer que a comunicação só funciona quando ela tem charme, provoca emoção. Quanto da sua emoção existe no filme?

Cao Hamburger: Me coloquei inteiramente à disposição do filme; emocionalmente, me entreguei a ele. Deve haver muito de mim, mas são coisas mais subjetivas. A história do filme não é autobiográfica, mas fiz o filme tentando me colocar sempre naquela situação e trazendo coisas das minhas emoções para aquela situação. 
comunicação \& educação • Ano XII • Número 2 • maio/ago 2007

C \& E: Como os seus filhos viram o filme? Qual a idade deles?

Cao Hamburger: Eles têm 16 e 17 anos. O Tom, que é o mais velho, foi às filmagens. Acho que eles chegaram a ler o roteiro antes; então, já são espectadores não muito distantes, estão envolvidos e me vêem no processo. Mas a Carolina, minha filha, assistiu ao filme pela primeira vez depois de pronto. Eles têm um interesse muito grande por essa época. Foi a partir deles que notei que os jovens poderiam se interessar pelo filme, porque eles têm mesmo um interesse, principalmente pelo fato de os jovens daquela época buscarem um ideal, batalharem por alguma coisa. Acho que os jovens de hoje têm uma visão meio romântica daquela época nesse sentido e, enfim, sempre são muito importantes para o meu trabalho. Sempre os ouço bastante, presto atenção no que estão falando.

C \& E: Essa revisão histórica, um pouco autobiográfica, serve como ponte entre gerações. Seu pai dizia que a televisão era uma "caixa maldita", mas, na vida acadêmica, ele procurou desmistificar isso, com uma grande contribuição em divulgar a ciência a um público maior. Você acompanhou essa transição?

Cao Hamburger: Acompanhei, até porque entendo essa coisa da caixa maldita, e senti também como pai, por conta dessa característica invasiva da televisão. Ela é um aparelho doméstico que você liga e seus filhos, quando pequenos, são capturados por aquele negócio. Então, dá muita aflição mesmo. A minha relação com a televisão também é de amor e ódio... eu também a odeio e a acho uma caixa maldita. Mas, enfim, também entendo que possa ser bem utilizada, possa ser uma coisa interessante.

C \& E: Ele inclusive propôs o Minuto científico na Estação Ciência e tem toda uma abertura para os meios de comunicação.

Cao Hamburger: Acredito que ele e minha mãe foram muitos espertos porque, apesar de ele chegar em casa e gritar "Desliga essa caixa maldita!", a política deles não era de proibição, nunca foi. Não sei se conscientemente ou não, eles foram cuidando para que nós - somos cinco irmãos... é uma audiência e tanto! - fôssemos adquirindo esse espírito crítico em relação à televisão, a tudo. Acredito que esse é o grande segredo, você conseguir - os pais, as escolas e os educadores - usar a televisão, pegá-la como uma realidade e desenvolvê-la. As escolas poderiam fazer isso também, além dos pais, de promover a discussão sobre o meio, pegar programas televisivos e discuti-los dentro da sala de aula. Isso vai dando ao aluno, ao espectador, um espírito crítico. Discutir é a melhor defesa; é uma relação mais saudável com esse veículo de massa que é tão presente. Meus pais fizeram um pouco isso. Atualmente, a principal atividade do meu pai é a divulgação científica. Ele criou esse Minuto científico e, se pudesse, faria muito mais coisas na televisão. 


\section{Um filme com muitas portas - Cristina Costa e Consuelo Ivo}

C \& E: Temos na revista duas seç̃es, Videografia, da Inês Carlos Magno, e Atividades em Sala de Aula, da Ruth Ribas Itacarambi. Elas sugerem filmes e atividades para o professor realizar com os alunos. Vocês pensaram em algo nesse sentido também?

Cao Hamburger: Sim, estamos incentivando as escolas a usarem o filme na sala de aula ${ }^{1}$. As que usaram este ano, nos deram um feedback, e foi incrível.

Resumo: O cineasta Carlos Império Hamburger, o Cao, comenta nesta entrevista o seu segundo longa-metragem, o aclamado $O$ ano em que meus pais saíram de férias. O também diretor de Castelo Rá-tim-bum, O Filme e da série para a TV que deu origem ao filme - vencedora de prêmios em todo o mundo -, fala da sua relação com o cinema e a televisão, e das possíveis saídas para uma audiência mais crítica nas salas de aula.

Palavras-chave: Cao Hamburger, cinema, televisão, educação, recepção.
Abstract: The movie maker Carlos Império Hamburger, known as $\mathrm{CaO}$, comments his second feature film, the acclaimed $O$ ano em que meus pais saíram de férias. Also director of Castelo Rá-tim-bum, $O$ Filme - and of the series that originated the motion picture, awarded all over the world -, he talks on his relationship with cinema and television, and on the possibilities of forming a more critical audience in classrooms.

Keywords: Cao Hamburger, cinema, television, education, reception.
1. Para a escola interessada em trabalhar o filme em sala de aula, a solicitação do material de apoio pedagógico pode ser feita pelo site <http://www. oano.com.br>. 